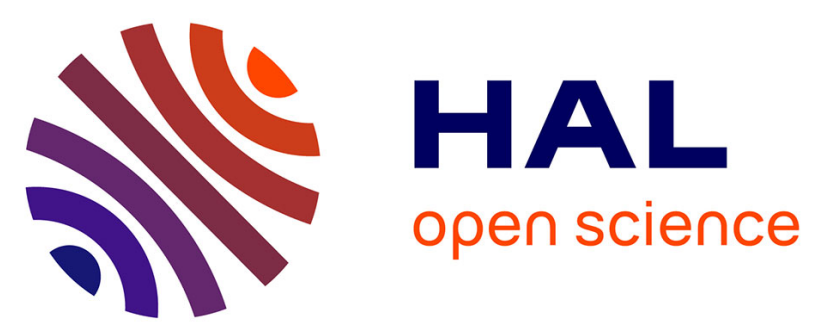

\title{
Micro-PIXE characterization of interactions between a sol-gel derived bioactive glass and biological fluids
} Jonathan Lao, Jean-Marie Nedelec, Philippe Moretto, Edouard Jallot

\section{To cite this version:}

Jonathan Lao, Jean-Marie Nedelec, Philippe Moretto, Edouard Jallot. Micro-PIXE characterization of interactions between a sol-gel derived bioactive glass and biological fluids. Nuclear Instruments and Methods in Physics Research Section B: Beam Interactions with Materials and Atoms, 2006, 245, pp.511-518. 10.1016/j.nimb.2005.12.049 . hal-00154776

\section{HAL Id: hal-00154776 https://hal.science/hal-00154776}

Submitted on 14 Jun 2007

HAL is a multi-disciplinary open access archive for the deposit and dissemination of scientific research documents, whether they are published or not. The documents may come from teaching and research institutions in France or abroad, or from public or private research centers.
L'archive ouverte pluridisciplinaire HAL, est destinée au dépôt et à la diffusion de documents scientifiques de niveau recherche, publiés ou non, émanant des établissements d'enseignement et de recherche français ou étrangers, des laboratoires publics ou privés. 


\section{Micro-PIXE characterization of interactions between a sol-gel derived bioactive glass and biological fluids}

J. LAO ${ }^{*}$, J.M. NEDELEC ${ }^{2}$, Ph. MORETTO ${ }^{3}$, E. JALLOT ${ }^{1}$.

${ }^{1}$ Laboratoire de Physique Corpusculaire de Clermont-Ferrand CNRS/IN2P3 UMR 6533

Université Blaise Pascal - 24 avenue des Landais, 63177 Aubière Cedex, France.

${ }^{2}$ Laboratoire des Matériaux Inorganiques CNRS UMR 6002

Université Blaise Pascal - 24 avenue des Landais, 63177 Aubière Cedex, France.

${ }^{3}$ Centre d’Etudes Nucléaires de Bordeaux Gradignan CNRS/IN2P3 UMR 5797

Université Bordeaux 1 - Chemin du Solarium, Le Haut-Vigneau, BP 120, 33175 Gradignan Cedex, France.

*Corresponding author:

Jonathan LAO

Laboratoire de Physique Corpusculaire de Clermont-Ferrand CNRS/IN2P3 UMR 6533

Université Blaise Pascal - 24 avenue des Landais, 63177 Aubière Cedex, France.

Tel : $33(0) 473407651$

Fax : $33(0) 473264598$

E-mail : lao@clermont.in2p3.fr 


\section{Abstract}

Bioactive glasses possess the ability to bond to living tissues through the formation of a calcium phosphate-rich layer at their interface with living tissues. This paper reports the different steps of this bioactivity process via a complete micro-PIXE characterization of a solgel derived $\mathrm{SiO}_{2}-\mathrm{CaO}$ bioactive glass in contact with biological fluids for different delays. Multi-elemental cartography at the glass/biological fluids interface together with major and trace elements quantification permit a better understanding of the five reaction stages involved in the bioactivity mechanisms. The presence of phosphorus was detected at the periphery of the material within $6 \mathrm{~h}$ of interaction with biological fluids. A calcium phosphate-rich layer containing magnesium is formed after a few days of interaction and presence of bone-like apatite is deduced from the calculation of the $\mathrm{Ca} / \mathrm{P}$ ratio at the material interface. That is of deep interest for clinical applications, because this biologically active behavior results in the formation of a strong interfacial bond between the glass and host tissues, and will stimulate bone-cell proliferation.

PACS: 68.08.-p, 81.05.Kf, 81.20.Fw, 82.80.Ej, 82.80.Yc, 87.64.Gb, 87.68.+z

Keywords: PIXE-RBS methods; biomaterials; bioactive glass; sol-gel. 


\section{Introduction}

Bioactive materials have been developed to preserve the comfort of living of people suffering from functional deficiency. They are widely used in surgical therapeutics for filling bony defects, solving cardiovascular and articular problems, repairing conductive hearing loss and in a growing number of clinical applications [1]. In contact with body fluids, bioactive materials induce a specific biological response at their surface which permits an intimate bonding to living tissues [2]. Due to a series of physico-chemical reactions occurring at the surface of the material, the bone-bonding ability consists to the formation of a carbonatecontaining hydroxyapatite $\left(\mathrm{Ca}_{10}\left(\mathrm{PO}_{4}\right)_{6}(\mathrm{OH})_{2(1-x)}\left(\mathrm{CO}_{3}\right)_{\mathrm{x}}\right)$ layer similar to the mineral composition of bone [3]. This property is known as bioactivity.

When put in contact with tissues, biological glasses show biocompatibility and absence of inflammatory response. They can be bioinert or bioactive depending on their composition and their textural properties. Dissolution of calcium and silicate ions from glasses plays an important role in forming the apatite layer [4]. The recognition that the material textural properties are a critical element for the formation of the bonding bone-like apatite layer is a major argument to use the sol-gel process. It permits the synthesis of a bioactive glass with an initial high specific surface area [5]. Further motivations for sol-gel processing are the potentially higher purity and homogeneity, the lower processing temperatures associated with sol-gel derived materials compared with traditional glass melting or ceramic powder methods and the relative economics of sol-gel methods in general. [6]. Another strong advantage of the sol-gel process is the possibility to produce materials in various shapes such as monoliths, powders, fibers or coatings. 
Sol-gel glasses in the $\mathrm{SiO}_{2}-\mathrm{CaO}$ system have been proved to form a calcium phosphate-rich layer at their surface. The initially amorphous calcium phosphate then crystallizes into an apatite analogous to that present in bone. The apatite crystals, reinforced by collagen fibers, form the bonding layer between the bioactive material and the living tissues [7]. The aim of this paper is to report the synthesis of a $\mathrm{SiO}_{2}-\mathrm{CaO}$ bioactive glass by sol-gel processing and to characterize the acellular in vitro development of the calcium phosphate-rich layer on its surface during interactions with biological fluids. For this purpose, bioactive glass samples were immersed in biological fluids for varying time periods. Knowledge of the elemental distribution at the bioactive glass periphery is important to understand the physico-chemical mechanisms that lead to the formation of a calcium phosphate layer [8]. This analysis was performed by Particle-Induced X-Ray Emission (PIXE) and Rutherford Backscattering Spectroscopy (RBS). These ion beam analysis methods allow us to measure the elemental composition of the glass immersed samples at the micrometer scale and to obtain elemental maps together with major and trace elements quantification.

\section{Materials and methods}

\section{Preparation of the bioactive glass samples}

Gel-glass powders containing 75 weight $\% \mathrm{SiO}_{2}-25$ weight $\% \mathrm{CaO}$ were prepared using the sol-gel process. Low-viscosity sol was obtained by mixing tetraethylorthosilicate (TEOS) and $\mathrm{Ca}\left(\mathrm{NO}_{3}\right)_{2} .4 \mathrm{H}_{2} \mathrm{O}$ in ethanol EtOH, $99 \%$. Deionised water was added with a water to alkoxide ratio equal to $12.2 \mathrm{~N} \mathrm{HCl}$ was used as a catalyst for the hydrolysis of TEOS. The prepared sol was then transferred to an oven at $60^{\circ} \mathrm{C}$ for gelation. Four hours later, the gelation began and the obtained gel was dried at $125^{\circ} \mathrm{C}$ for 24 hours. At this time, the xerogel appears as a white powder and is finally heated at $700^{\circ} \mathrm{C}$ for 24 hours to achieve nitrate 
elimination and further densification. The dry gel powder was then compacted into discs of 13 mm diameter and $2 \mathrm{~mm}$ height.

\section{Material characterization}

We used Inductively Coupled Plasma-Atomic Emission Spectroscopy (ICP-AES) to determine the chemical composition of the bioactive glass powder. The nominal and experimental glass compositions are presented in table 1.

The textural characterization of the samples was performed on a Coulter SA 3100 gas sorption system. The sample was vacuum outgassed at $120^{\circ} \mathrm{C}$ for 12 hours to remove physically adsorbed molecules such as moisture from the pores, and analyzed with nitrogen adsorption and desorption. The instrument determined isotherms volumetrically by a discontinuous static method at $77 \mathrm{~K}$. The surface area was obtained by applying the BET method [9] to the $\mathrm{N}_{2}$ isotherm. The pore size distribution was determined by the $\mathrm{BJH}$ method [10] on the desorption branch. Total pore volume was measured at a relative pressure $\mathrm{P} / \mathrm{P}_{0}=0.99$.

\section{In vitro studies}

The glass discs were immersed at $37^{\circ} \mathrm{C}$ for 1,6 hours and 1, 2, 5, 10 days in $45 \mathrm{~mL}$ of a standard Dulbecco’s Modified Eagle Medium (DMEM, Biochrom AG, Germany), which composition is almost equal to human plasma. After interaction, the discs were removed from the fluid, air dried and embedded in resin (AGAR, Essex, England). Before characterization, thin sections of 30 micrometers nominal thickness were prepared using a Leica RM 2145 microtome. Cutting is made perpendicular to the surface of the glass discs. Then, the sections are placed on a mylar film with a hole of $3 \mathrm{~mm}$ in the centre. Measurements are performed on the area of the section placed over the hole. 


\section{PIXE-RBS analysis}

PIXE and RBS methods are used simultaneously. The PIXE method permits to identify and to quantify locally major and trace elements at the biomaterial/biological fluids interface. The RBS method is used to determine the electric charge received by the samples during irradiation. This parameter is absolutely necessary for PIXE spectra quantification [11].

Analyses of the biomaterial/biological fluids interface were performed using nuclear microprobes at CENBG (Centre d’Etudes Nucléaires de Bordeaux-Gradignan, France). The device provides a micro-beam line employed for ion beam analytical measurements at the microscopic level. The experimental characteristics of the CENBG nuclear microprobe have been published previously [12]. For PIXE analyses, we chose proton scanning micro-beam of 1.5 MeV energy and $100 \mathrm{pA}$ in intensity to ionize atoms of the glass samples. The beam diameter was nearly $2 \mu \mathrm{m}$. Such parameter values are justified by a higher ionization crosssections of light elements $(\mathrm{Z}<20)$ and a better sensitivity resulting for PIXE analysis by using a detector without filter. Furthermore, weak intensity and the choice of protons as the ion beam allow the target degradation to be minimized during irradiation. However, the intensity is not too weak and permits measurement duration under 1 hour.

An $80 \mathrm{~mm}^{2} \mathrm{Si}(\mathrm{Li})$ detector was used for X-ray detection. The $\mathrm{Si}(\mathrm{Li})$ semiconductor was orientated at $135^{\circ}$ with respect to the incident beam axis and equipped with a beryllium window $12 \mu \mathrm{m}$ thick. PIXE spectra are treated with the software package GUPIX, developed at Guelph University, Canada [13]. GUPIX determines the intensities of characteristic X-ray peaks in a PIXE spectrum by fitting a model spectrum to the measured one using the nonlinear least squares technique, together with subsequent conversions of the fitted X-ray peak intensities to elemental concentrations via defined standardization technique (involving solid angle of detection, relative charge and user-determined instrumental constants). 
Relating to RBS, a silicon particle detector placed $135^{\circ}$ from the incident beam axis allowed us to monitor the total number of protons that interacted with the sample via the yield of backscattered particles. Data were treated with the SIMNRA code developed at the MaxPlanck-Institut für Plasma Physik, Germany [14].

\section{Results}

\section{Characterization of the glass powder before the in vitro assays}

Thanks to sol-gel processing, bioactive glass powders were obtained with a good agreement between nominal and experimental concentrations of $\mathrm{Ca}$ and Si oxides determined by ICP-AES (Table 1). The textural properties are summarized in Table 2. The synthesized $\mathrm{SiO}_{2}-\mathrm{CaO}$ glass is a mesoporous material, with a modal pore diameter of $71.4 \AA$ (calculated by the BJH method). That is typical of sol-gel derived materials. Such textural characteristics will have major effects on the material dissolution and kinetics of physico-chemical reactions at its surface, and thus influence the bioactivity process and the calcium phosphate-rich layer formation.

\section{Evaluation of irradiation damages}

Micro-beam can cause target degradation [15]. These damages induce mass losses which will affect the elemental concentration determinations. Scanning micro-beam protects sample only if the amount of deposited charge is small [16]. Verifying the behavior of our samples under irradiation is thus essential to be ensured of the accuracy of the measured concentrations. We irradiated a sample of the primary synthesized $\mathrm{SiO}_{2}-\mathrm{CaO}$ bioactive glass for $1 \mathrm{~h}$. By examination of the RBS data, we determined the total electric charge deposited. We finally obtained Si and Ca concentrations in the sample with intervals of regular times that are equivalent with percentage of the total deposited charge (Figure 1). Our samples are 
relatively stable during irradiation. When the samples are irradiated, part of oxygen and hydrogen volatilizes, causing matrix calculation to be distorted. This phenomenon explains the fluctuations in the elemental concentration determination, which are in the order of $5 \%$.

\section{Micro-PIXE study of the discs}

The PIXE method permits elemental cartography at the micrometer level. Elemental maps across the periphery of the $\mathrm{SiO}_{2}-\mathrm{CaO}$ glass were recorded for each immersion time in DMEM. Then, quantification of major and trace elements was performed by mean of GUPIX.

In Figure 2, we present multi-elemental maps across the periphery of the primary $\mathrm{SiO}_{2}-\mathrm{CaO}$ glass before immersion into DMEM. We detect the initial elements ( $\mathrm{Si}, \mathrm{Ca}$ ) of the glass and $\mathrm{Cl}$ which is a resin component. On the maps, we clearly observe two zones. The first area is composed with $\mathrm{Si}$, Ca and represents the bioactive glass. The second is composed with $\mathrm{Cl}$ and shows the presence of resin at the surface of the glass disc. The glass disc has a homogeneous composition. On both Si and Ca maps, we can note the presence of white areas in the glass, indicating that the section is locally torn.

After $1 \mathrm{~h}$ of interaction, the presence of $\mathrm{P}$ is detected at the periphery of the glass, as well as low concentration of $\mathrm{Mg}$ (data not shown). Concerning Si and $\mathrm{Ca}$, a gradient of concentration is observed from the periphery of the material to the centre of the glass disc.

Figure 3 shows the multi-elemental maps of a disc sample after $6 \mathrm{~h}$ of interaction with biological fluids. We observe two areas at bioactive glass disc surface. The first area is composed with $\mathrm{Si}, \mathrm{Ca}$ and represents the glass in dissolution. The second area is at the surface of the glass and is essentially composed with $\mathrm{Si}$, Ca, and P together with traces of Mg. The thickness of this layer is about $10 \mu \mathrm{m}$. It clearly appears that the glass is in dissolution, as Ca is removed from the network. After 10 days of interaction with biological fluids (Figure 4), three areas appear. The inner glass consists of the primary silicate network enduring 
dissolution. A homogeneous calcium phosphate-rich layer is formed at the material surface. This layer contains $\mathrm{Mg}$ and its thickness is in the order of $15 \mu \mathrm{m}$. Between those areas, we observe the presence of a thin calcium-enriched layer.

Thus, we examined variations relative to immersion time of $\mathrm{Si}, \mathrm{Ca}, \mathrm{P}$ and $\mathrm{Mg}$ concentrations at both the material periphery (Figure 5) and within the glass disc (Figure 6). At the periphery of the glass, Ca concentration decreases by 30\% during the first $6 \mathrm{~h}$ of soaking (Figure 5). Despite some variations, Si concentration tends to decrease during this time period. $\mathrm{P}$ is blended into the material in an obvious way, since its concentration increases up to $44000 \mathrm{ppm}$ after $6 \mathrm{~h}$ of immersion. The local increase of phosphorus concentration is highlighted in Figure 3. Between $6 \mathrm{~h}$ and 2 days of soaking, Ca and P concentrations roughly increase. On the contrary, Si concentration significantly decreases. These concentrations continue to increase with time of exposure to DMEM and after 10 days of immersion, the phosphorus amount at the glass periphery reaches up to $12 \%$ weight. Concerning $\mathrm{Mg}$, it appears after $1 \mathrm{~h}$ of immersion and its concentration remains almost the same during the assays. This element was incorporated with the calcium phosphate-rich layer as a trace element (as visible in Figure 4).

In the inner glass, $\mathrm{Si}$ and Ca showed totally opposed behaviors (Figure 6). Between $1 \mathrm{~h}$ and 2 days, certain fluctuations in the values of Si and Ca concentrations were observed. $\mathrm{P}$ and Mg concentrations are low. They evolved in the same way, reaching a peak value after 1 day of exposure. After 2 days, both Si and Ca concentrations gradually returned to their initial values, while $\mathrm{P}$ and $\mathrm{Mg}$ concentrations were almost null.

Figure 7 shows the evolution of the $\mathrm{Ca} / \mathrm{P}$ atomic ratio at the periphery of the glass (Ca$\mathrm{P}$ layer) for each immersion time. The $\mathrm{Ca} / \mathrm{P}$ atomic ratio progressively decreases and remains equal to 2.0 after 5 days. This result shall be confronted to the $\mathrm{Ca} / \mathrm{P}$ nominal value of pure hydroxyapatite which is equal to 1.7 . 


\section{Discussion}

\section{Physico-chemical reactions at the bioactive glass surface}

In this work, we study surface changes of sol-gel derived bioactive glass discs in the $\mathrm{SiO}_{2}-\mathrm{CaO}$ system and soaked in a biological solution. To better understand mechanisms of interaction between the bioactive glass and biological fluids a physico-chemical approach is used, namely the characterization of the modification kinetics of the discs periphery by means of PIXE-RBS methods. Micro-PIXE associated to RBS allow us to obtain quantitative elemental maps of all elements with $\mathrm{Z}>11$ at the micrometer scale. Thanks to PIXE method we are able to study major, minor and even trace elements (like Mg) with concentrations of a few ppm. After different delays of immersion in biological fluids, chemical maps across the periphery of glass discs show the physico-chemical reactions occurring at the surface of the glass disc.

During interactions between bioactive glass discs and biological fluids, the glass composition evolves with time of immersion. The different steps of bioactivity mechanism are visible in Figure 5 and Figure 6. Ca concentration decreases during the first 6 h. Si concentration at the periphery of the glass decreases by $10 \%$ after $1 \mathrm{~h}$ of interaction (loss of soluble silica to the solution). However, a silica-rich layer seems to be formed at the surface within $6 \mathrm{~h}$. At this time period, $\mathrm{P}$ and $\mathrm{Mg}$ are detected as trace elements at the surface of the glass. In the inner glass, Si and Ca concentrations evolve in an opposite way because Si and Ca oxides content represent nearly $100 \%$ of the glass. Fluctuations in $\mathrm{Si}$ and $\mathrm{Ca}$ concentrations during the first 2 days are explained by the deep structural changes occurring in the glass network, as well as dealkalization and calcium migration process leading to the appearance of a locally calcium-enriched layer. Figure 3 shows those changes, as well as the amorphous calcium phosphate layer formation concurrently beginning. Growth of this layer is 
proved by the significant increase of $\mathrm{Ca}$ and $\mathrm{P}$ concentrations at the glass surface. Finally, we obtain a multilayer material with the formation of a Ca rich layer and a Ca-P rich layer (Figure 4). Presence of $\mathrm{Mg}$ is detected in the calcium phosphate layer. $\mathrm{Mg}$ can play an important role during spontaneous formation of in vivo calcium phosphates and bone bonding $[17,18]$

The basis of bone-bonding property of bioactive glasses is the chemical reactivity of the material in contact with biological fluids [19]. The formation of the apatite layer occurs through physico-chemical reactions which can be decomposed into five steps [20, 21]. The first stage is the dealkalization of the surface by rapid exchange of $\mathrm{Ca}^{2+}$ cations with $\mathrm{H}^{+}$from solution. Hence, Ca concentration in the material decreased during the first $6 \mathrm{~h}$ of exposure to DMEM. This reaction is immediately followed by a breakdown of the silica network enduring dissolution, forming silanol bonds at the glass interface $\left(2^{\text {nd }}\right.$ stage $)$ that repolymerize to form a hydrated, high surface-area, silica-rich layer ( ${ }^{\text {rd }}$ stage). This silica rich surface attracts organic molecules and facilitates the formation of the apatite layer on the glass. Indeed, the $4^{\text {th }}$ reaction stage is the migration of $\mathrm{Ca}^{2+}$ groups from the glass to the surface through the $\mathrm{SiO}_{2}$ rich layer, followed by growth of the amorphous calcium phosphate-rich film by incorporation of soluble calcium and phosphates from solution. Finally, the $5^{\text {th }}$ reaction stage consists of the crystallization of the amorphous calcium phosphate by incorporation of $\mathrm{OH}^{-}$, $\mathrm{CO}_{3}{ }^{2-}$ anions and $\mathrm{Mg}^{2+}$ cations from solution to form an apatite layer.

The Ca-P layer formation ( $5^{\text {th }}$ stage) might be deduced from Figure 7 . After 5 days, the $\mathrm{Ca} / \mathrm{P}$ atomic ratio at the glass interface remains equal to 2.0 , which is near the characteristic apatite value of 1.7. This variation might be explained by the mechanism of apatite formation. The elements concentrations for the $\mathrm{Ca} / \mathrm{P}$ ratio calculation were determined across the $\mathrm{CaP}$ rich layer. However the crystallization of the amorphous calcium phosphate takes place on particular favorable sites for apatite nucleation, leading to the formation of an apatite-like 
phase consisting of small crystallites of estimated size $140 \AA$ [7, 22, 23]. Therefore, the Ca/P ratio calculation is distorted by the presence of amorphous calcium phosphate locally subsisting between nucleation sites. In addition, $\mathrm{Mg}^{2+}$ can substitute into the apatite lattice, causing its physico-chemical properties to change. In fact, apatite substituted with Mg results in a Ca deficient apatite with lower crystallinity and higher solubility [24, 25].

\section{Conclusion}

The results of the present work showed that the $\mathrm{SiO}_{2}-\mathrm{CaO}$ glass is able to induce the formation of an apatite layer, indicating that it is bioactive. Micro analysis with the PIXE method allowed us to specify the role of major elements ( $\mathrm{Si}, \mathrm{Ca}, \mathrm{P}$ ) and trace elements (Mg) in the physico-chemical reactions occurring at the periphery of the glass. Moreover, explicit multi-elemental maps were obtained, highlighting the calcium phosphate rich-layer formation and the evolution of the glass network.

The reason for choosing a glass in the $\mathrm{SiO}_{2}-\mathrm{CaO}$ binary system was first a higher homogeneity in the glass to be expected. Furthermore, the study of the Ca-P layer growth process was easier since the phosphate ions were only coming from the solution. The calcium phosphate-rich layer containing magnesium was quickly formed, following five reaction stages. It is important to notice that this layer grows up in an acellular environment and therefore its spontaneous formation was only due to the $\mathrm{SiO}_{2}-\mathrm{CaO}$ bioactive properties. The formation of biologically active apatite layer is a prerequisite to bond to host tissues. 


\section{References}

[1] L.L. Hench, J. Am. Ceram. Soc. 74 (1991) 1487.

[2] L.L. Hench, J.K. West, Life Chem. Reports 13 (1996) 187.

[3] L.L. Hench, R. Splinter, W. Allen, T. Greenlee, J. Biomed. Mater. Res. 2 (1971) 117.

[4] T. Kokubo, Biomaterials 12 (1991) 155.

[5] R. Li, A.E. Clark, L.L. Hench, J. Appl. Biomater. 2 (1991) 231.

[6] L.L. Hench, J.K. West, Chem. Rev. 90 (1990) 33.

[7] I. Izquierdo-Barba, A.J. Salinas, M. Vallet-Regí, J. Biomed. Mater. Res. 47 (1999) 243.

[8] E. Jallot, in: H.S. Nalwa (Ed.), Encyclopedia of Nanoscience and Nanotechnology vol.7, American Scientific Publishers, 2004, p.405.

[9] S. Brunauer, P.H. Emmet, E. Teller, J. Am. Chem. Soc. 60 (1938) 309.

[10] E.P. Barret, L.G. Joyner, P.P. Halenda, J. Am. Chem. Soc. 73 (1951) 373.

[11] Y. Barbotteau, J.L. Irigaray, E. Jallot, Surf. Interface Anal. 35 (2003) 450.

[12] Y. Llabador, P. Moretto, H. Guegan, Nucl. Instr. Meth. B 77 (1993) 123.

[13] J.A. Maxwell, W.J. Teesdale, J.L. Campbell, Nucl. Instr. Meth. B 95 (1995) 407.

[14] M. Mayer, Nucl. Instr. Meth. B 194 (2002) 177.

[15] B.J. Kirby, G.J.F. Legge, Nucl. Instr. Meth. B 54 (1991) 98.

[16] M. Cholewa, G. Bench, B.J. Kirby, G.J.F. Legge, Nucl. Instr. Meth. B 54 (1991) 101.

[17] E. Jallot, Appl. Surf. Sci. 211 (2003) 89. 
[18] E. Jallot, J.M. Nedelec, A.S. Grimault, E. Chassot, A. Grandjean-Laquerrière, P. Laquerrière, D. Laurent-Maquin, Colloids Surf. B 42 (2005) 205.

[19] P. Saravanapavan, J.R. Jones, R.S. Pryce, L.L. Hench, J. Biomed. Mater. Res. 66 A (2003) 110.

[20] J. Zhong, D.C. Greenspan, J. Biomed. Mater. Res. B 53 (2000) 694.

[21] E. Jallot, H. Benhayoune, L. Kilian, Y. Josset, Langmuir 19 (2003) 3840.

[22] T. Kokubo, H. Kushitani, S. Sakka, J. Biomed. Mater. Res. 24 (1990) 721.

[23] C. Ohtsuki, T. Kokubo, T. Yamamuro J. Noncryst. Solids 143 (1992) 84.

[24] R.Z. Legeros, R. Kijkowska, I. Kattech, M. Jemal, J.P. Legeros, J. Dent. Res. 65 (1983) 783.

[25] M. Vallet-Regí, A.J Salinas, J. Román, M. Gil, J. Mater. Chem. 9 (1999) 515. 


\section{Tables}

\begin{tabular}{lll}
\hline & nominal & experimental \\
\hline $\mathrm{SiO}_{2}$ (weight \%) & 75 & $72.20 \pm 0.37$ \\
$\mathrm{CaO}$ (weight \%) & 25 & $24.50 \pm 0.17$ \\
\hline
\end{tabular}

Table 1 : Nominal and experimental concentrations (weight \%) of Si and Ca oxides in the glass powder.

\section{$\mathrm{SiO}_{2}$-CaO glass powder}

\begin{tabular}{ll}
\hline Surface area & $26 \mathrm{~m}^{2} / \mathrm{g}$ \\
Pore volume & $0.94 \mathrm{~cm}^{3} / \mathrm{g}$ \\
Modal pore diameter & $71.4 \AA$ \\
\hline
\end{tabular}

Table 2 : Textural properties of the $\mathrm{SiO}_{2}-\mathrm{CaO}$ glass powder. 


\section{Figure captions}

Figure 1 : $\mathrm{Si}$ and Ca concentrations (ppm) in the synthesized $\mathrm{SiO}_{2}-\mathrm{CaO}$ glass versus deposited charge during irradiation (\%).

Figure 2 : $\mathrm{Si}$, $\mathrm{Ca}$ and $\mathrm{Cl}$ maps across the periphery of the synthesized $\mathrm{SiO}_{2}-\mathrm{CaO}$ glass before the in vitro assays $\left(275 \times 275 \mu \mathrm{m}^{2}\right)$.

Figure 3 : Si, Ca, P, Mg maps of the $\mathrm{SiO}_{2}-\mathrm{CaO}$ glass after $6 \mathrm{~h}$ of immersion in DMEM $(67 \times$ $\left.67 \mu \mathrm{m}^{2}\right)$

Figure 4 : $\mathrm{Si}$, $\mathrm{Ca}, \mathrm{P}, \mathrm{Mg}$ maps of the $\mathrm{SiO}_{2}-\mathrm{CaO}$ glass after 10 days of immersion in DMEM $\left(99 \times 99 \mu \mathrm{m}^{2}\right)$.

Figure 5 : evolution of $\mathrm{Ca}, \mathrm{P}, \mathrm{Mg}$ and Si concentrations (ppm) at the glass periphery with time of exposure to DMEM.

Figure 6 : evolution of $\mathrm{Ca}, \mathrm{P}, \mathrm{Mg}$ and Si concentrations (ppm) within the glass with time of exposure to DMEM.

Figure $7: \mathrm{Ca} / \mathrm{P}$ atomic ratio in the Ca-P layer versus time of exposure to DMEM. 


\section{Figures}

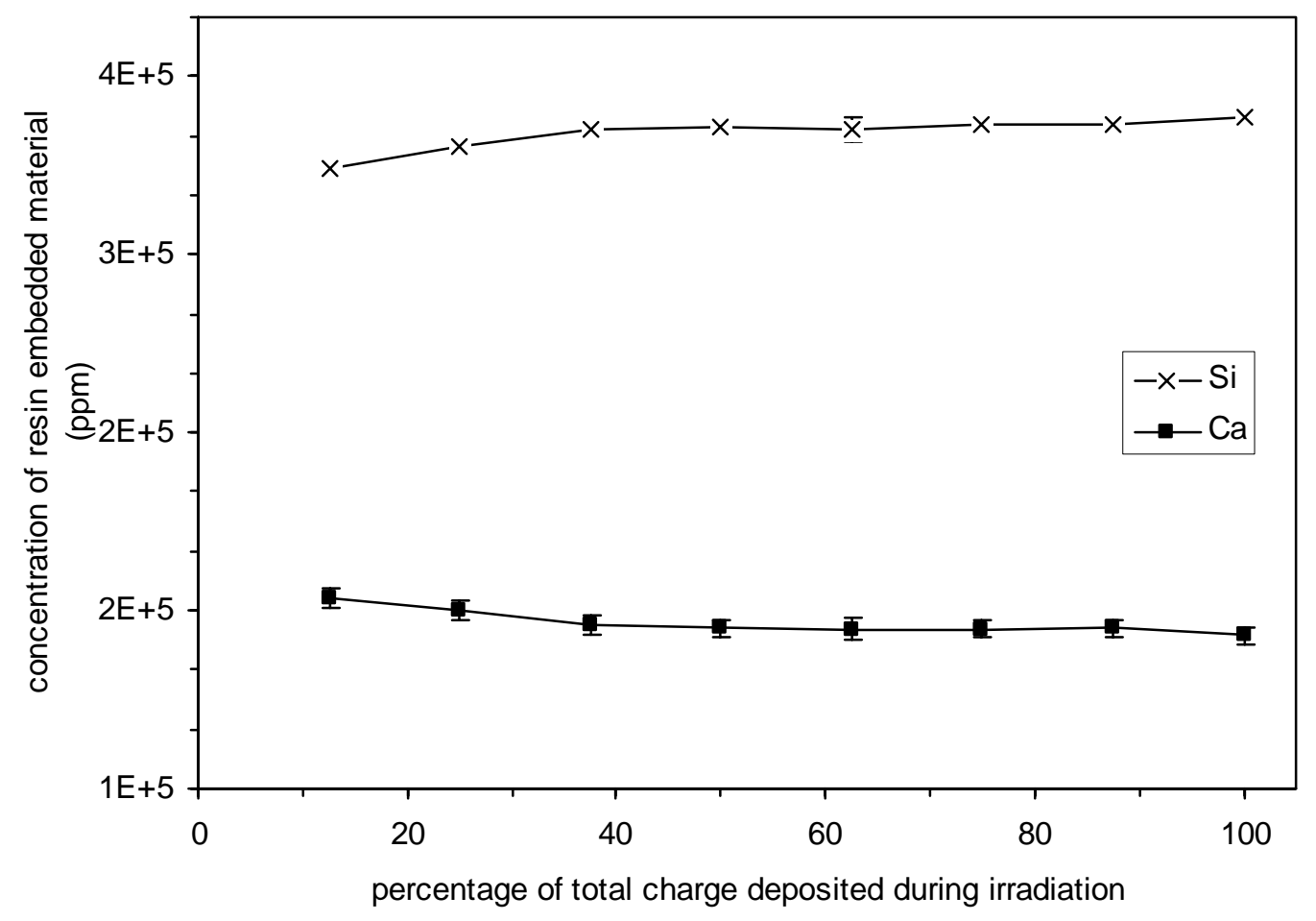

Figure 1 


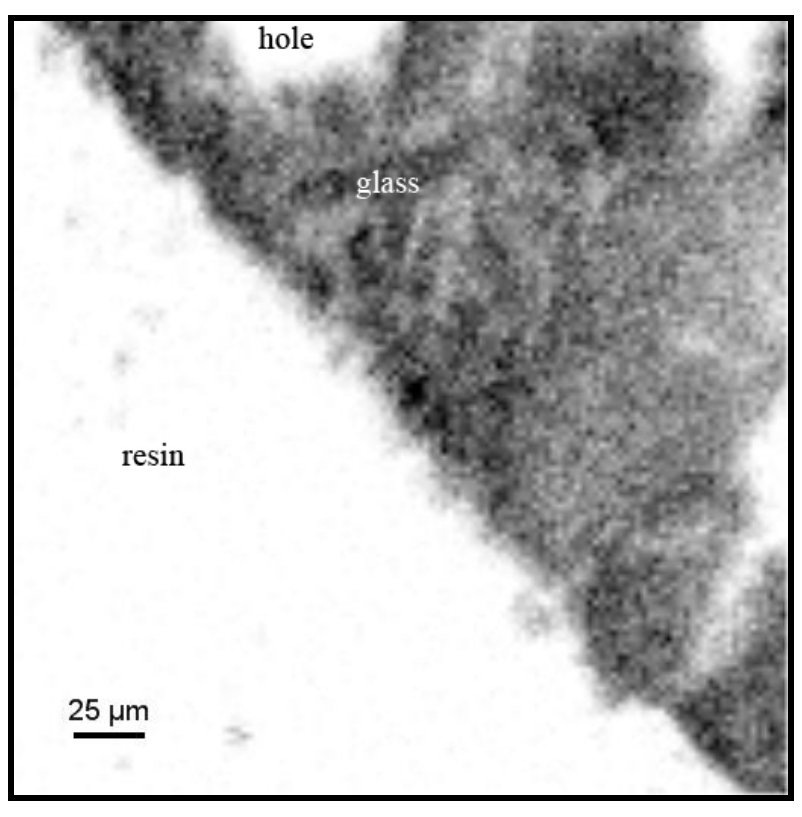

Ca

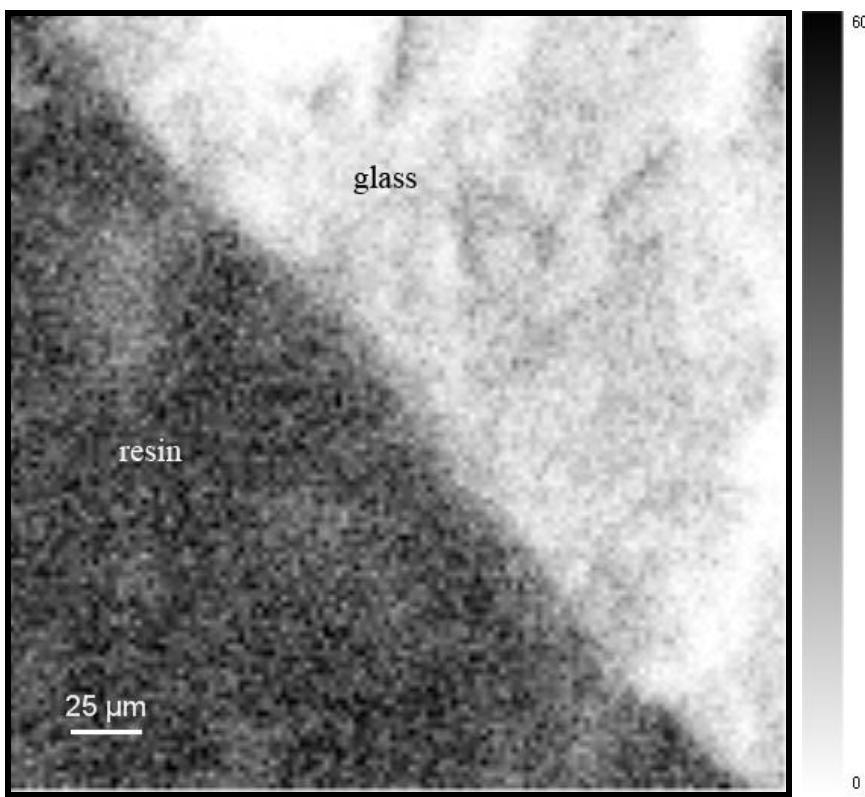

Cl

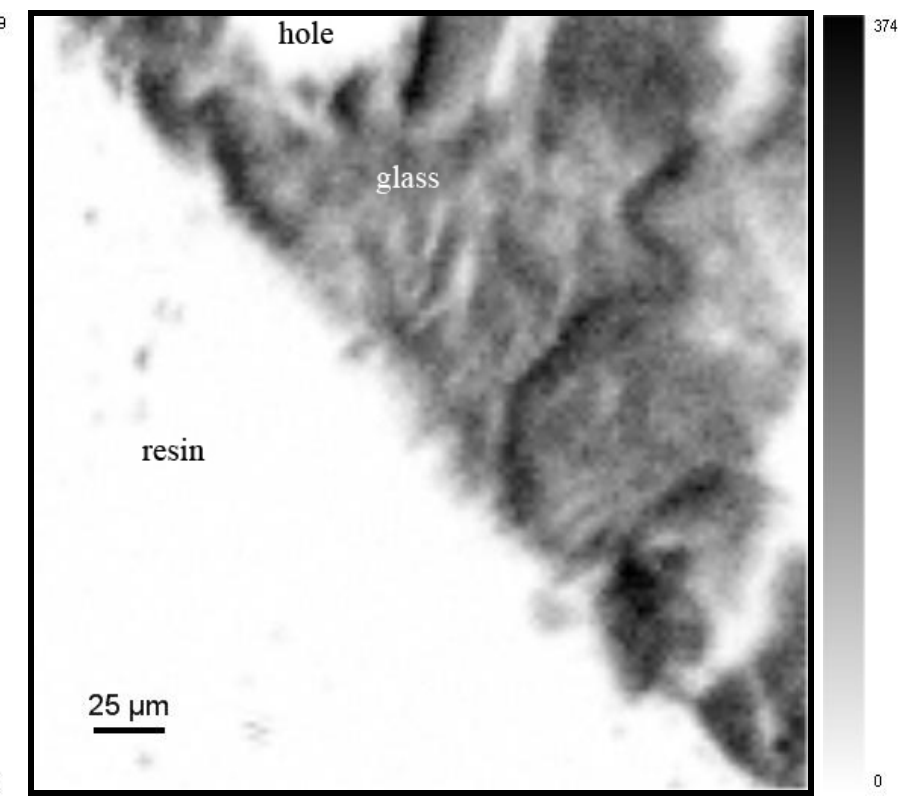

Si

Figure 2 


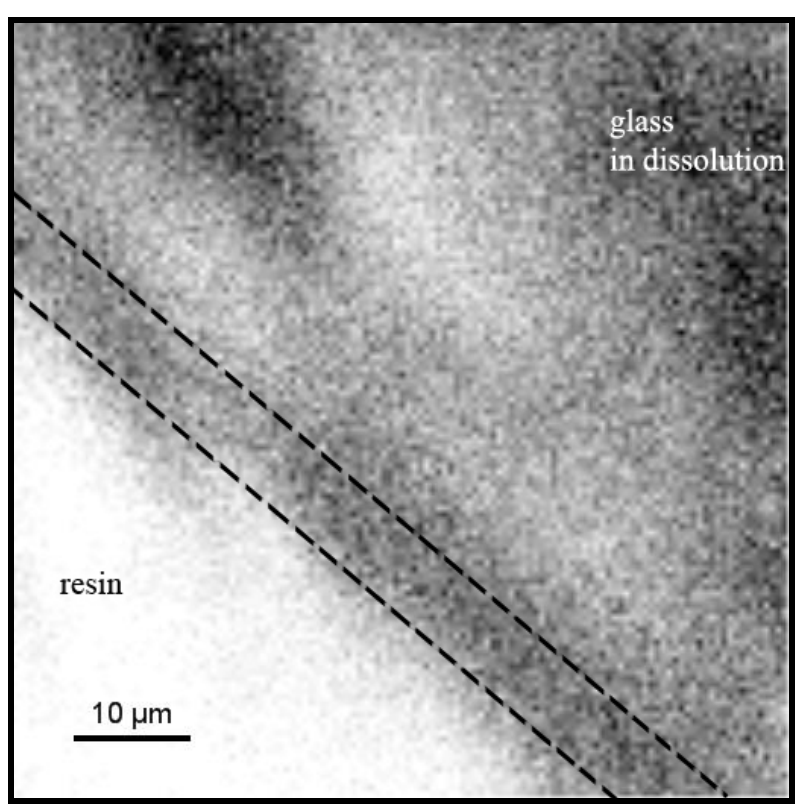

Ca

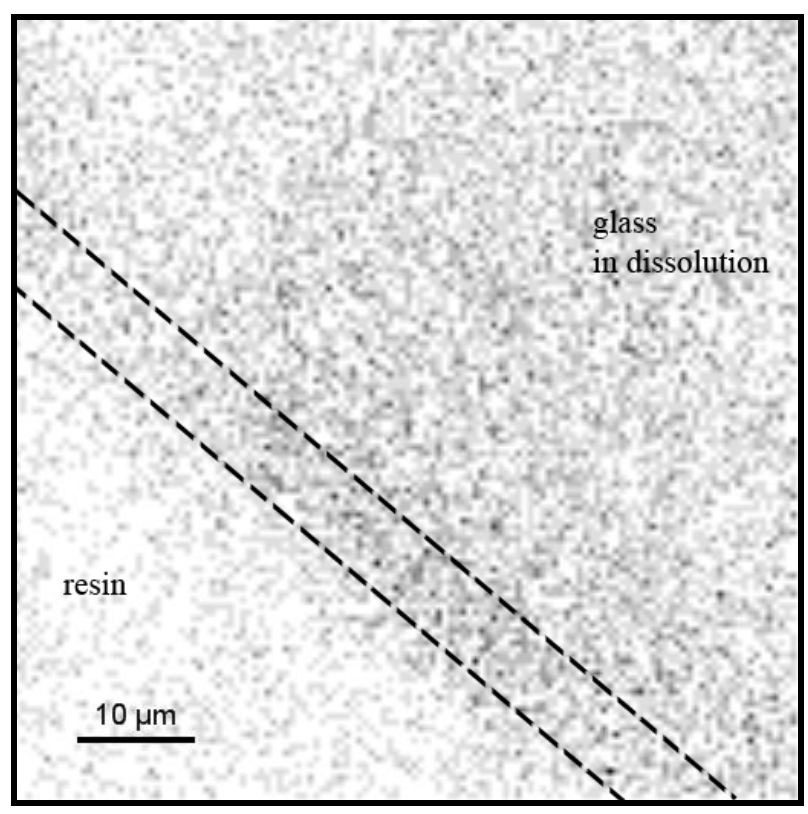

Mg

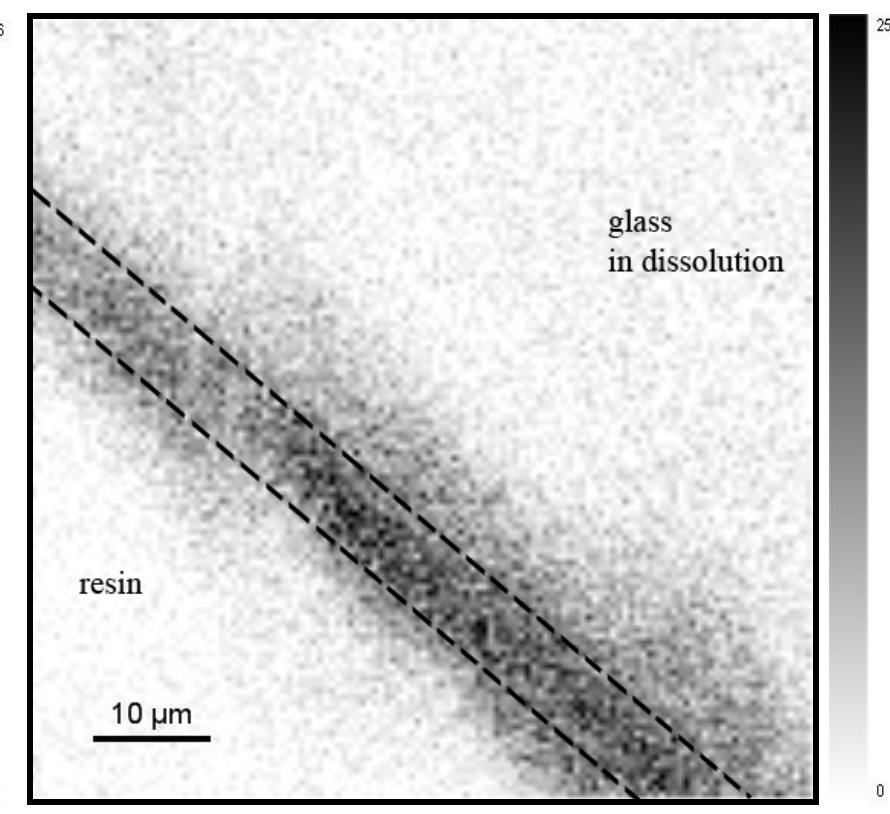

$\mathbf{P}$

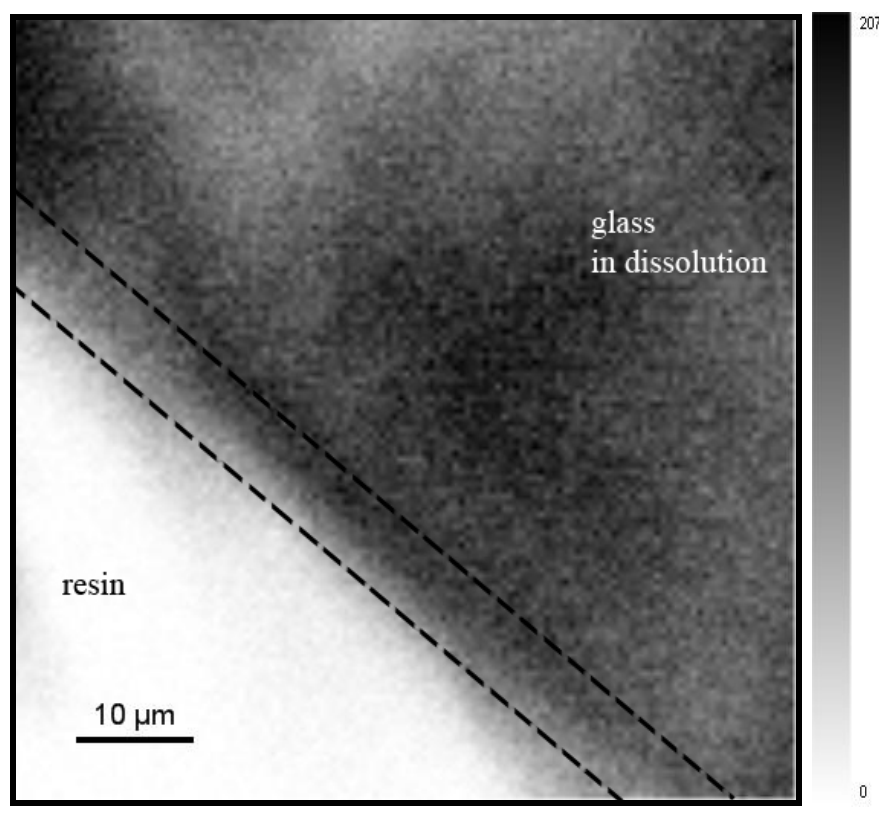

Si

Figure 3 


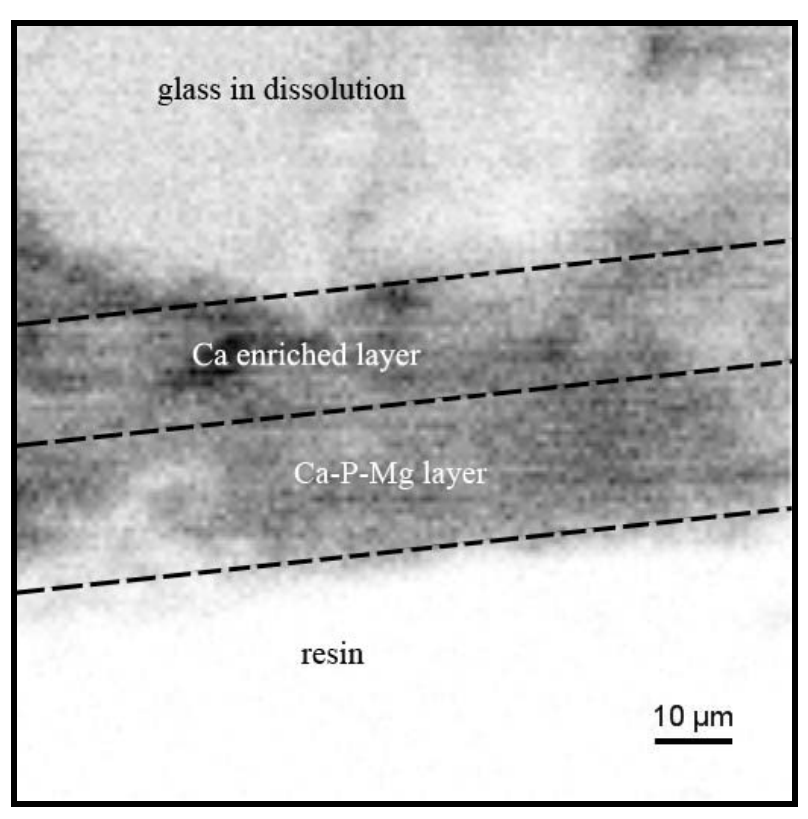

Ca

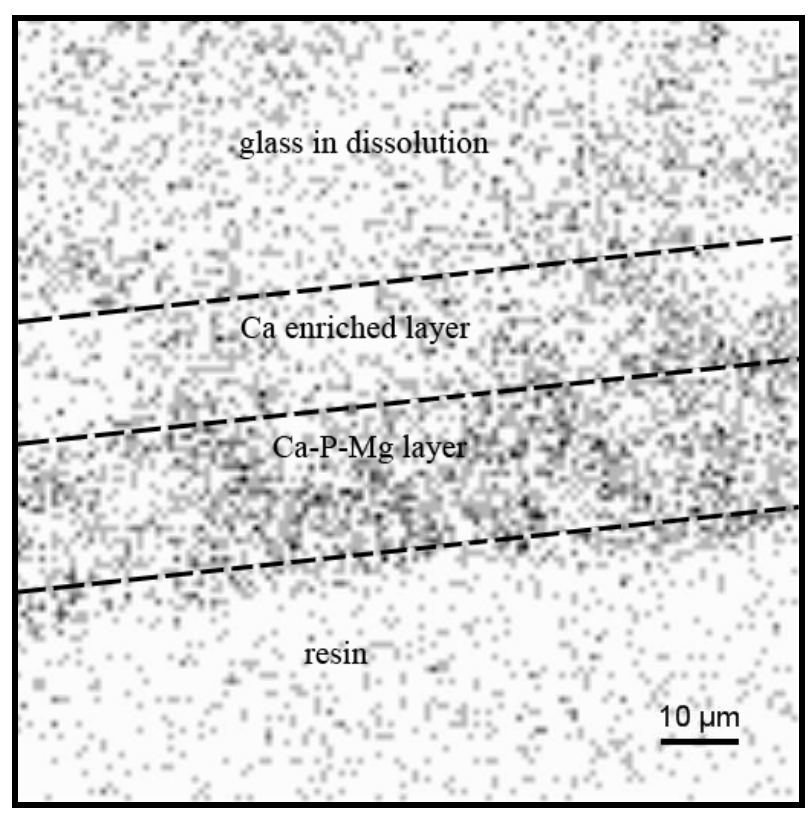

Mg

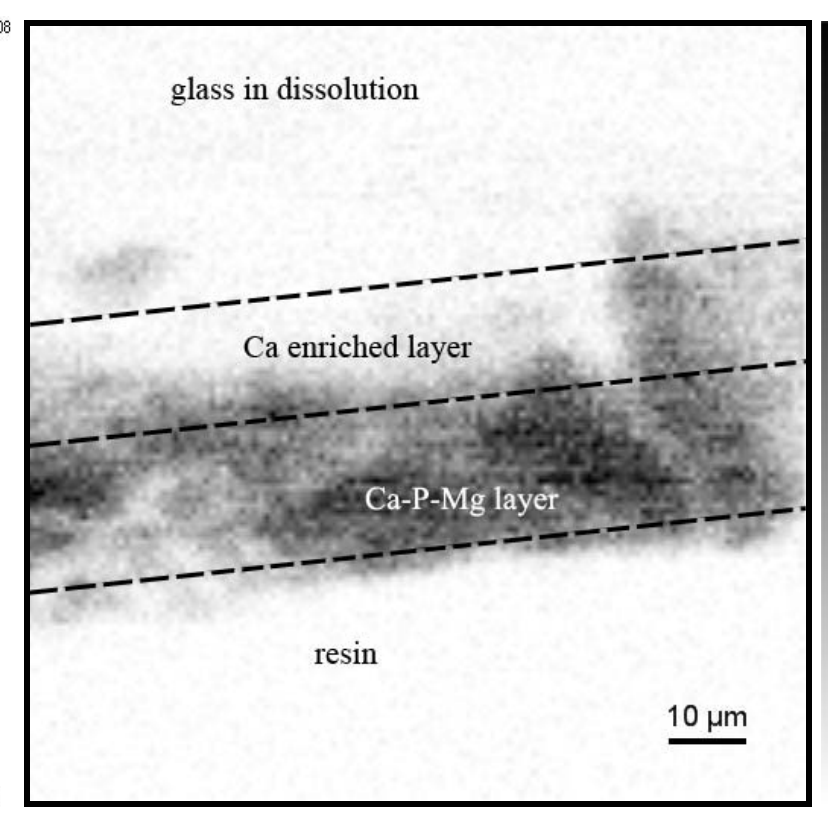

P

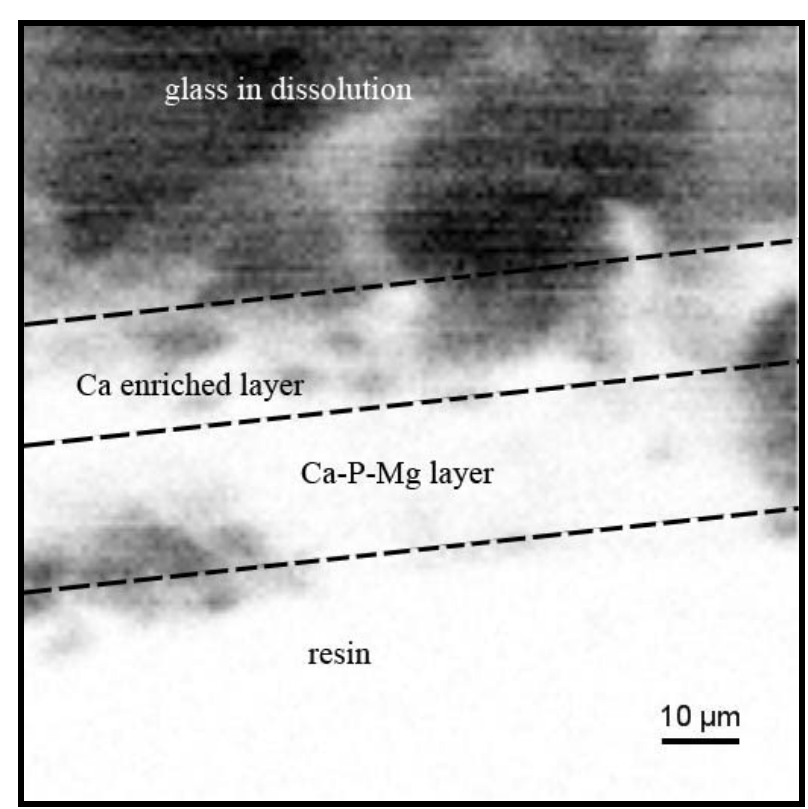

Si

Figure 4 


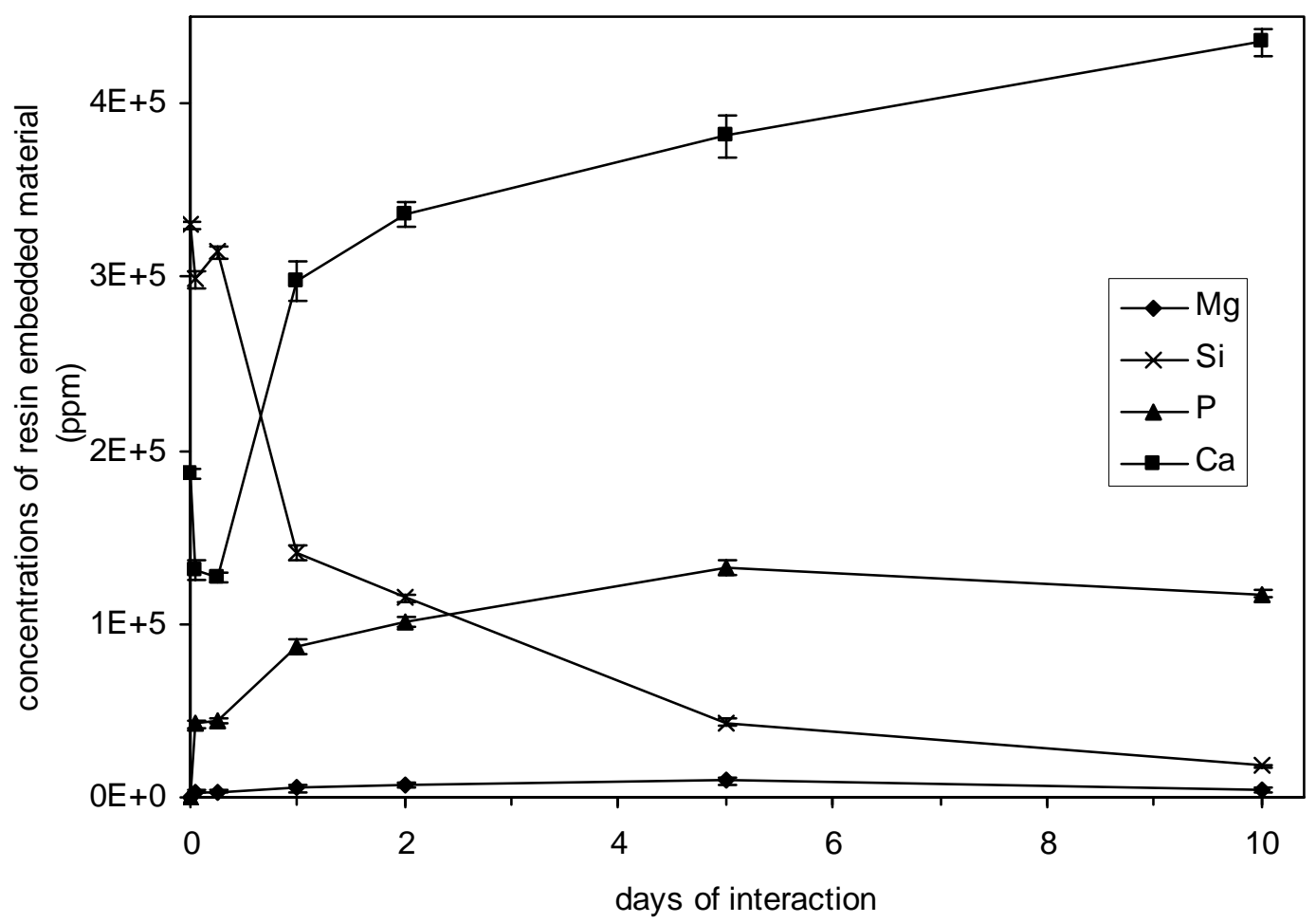

Figure 5

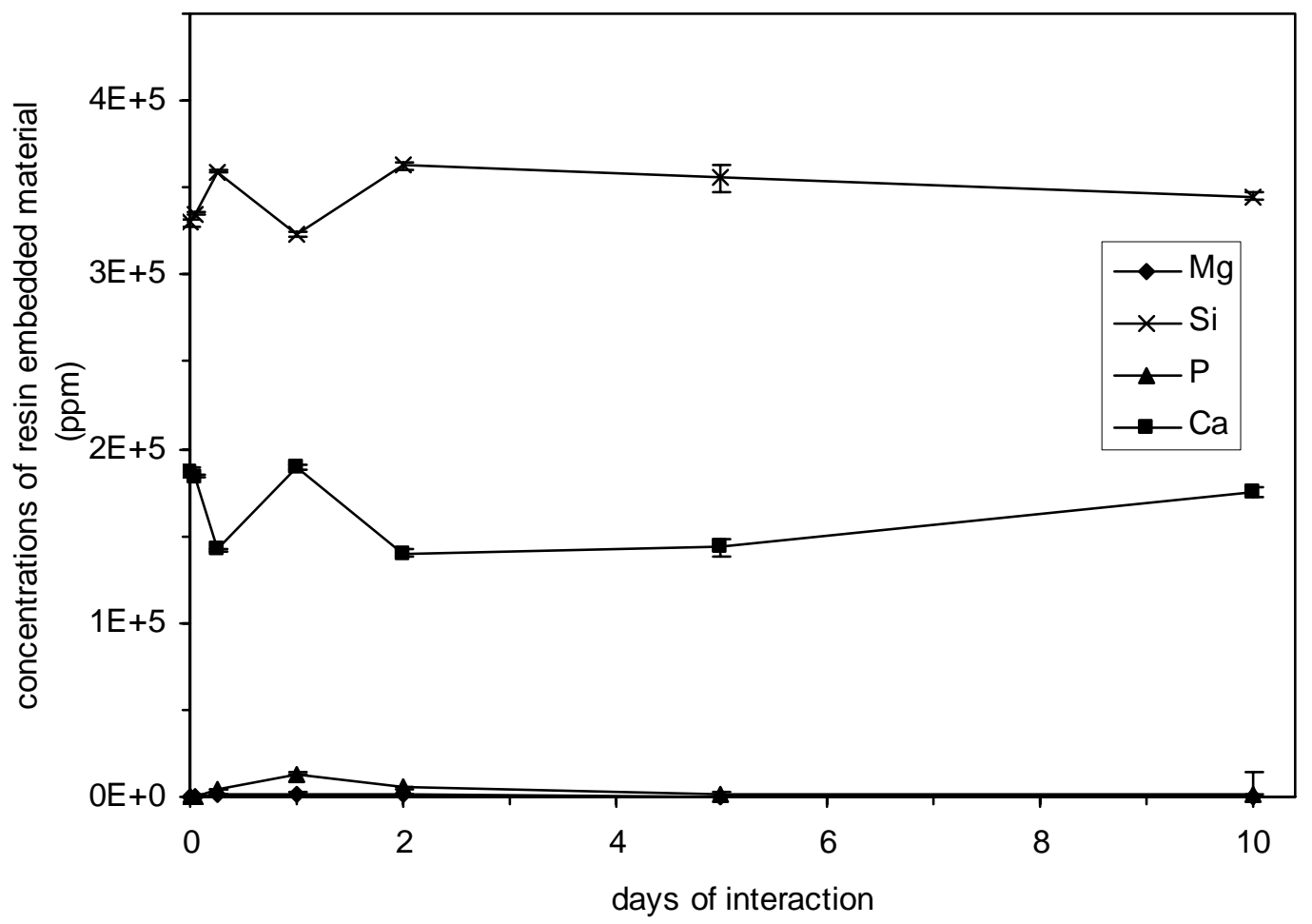

Figure 6 


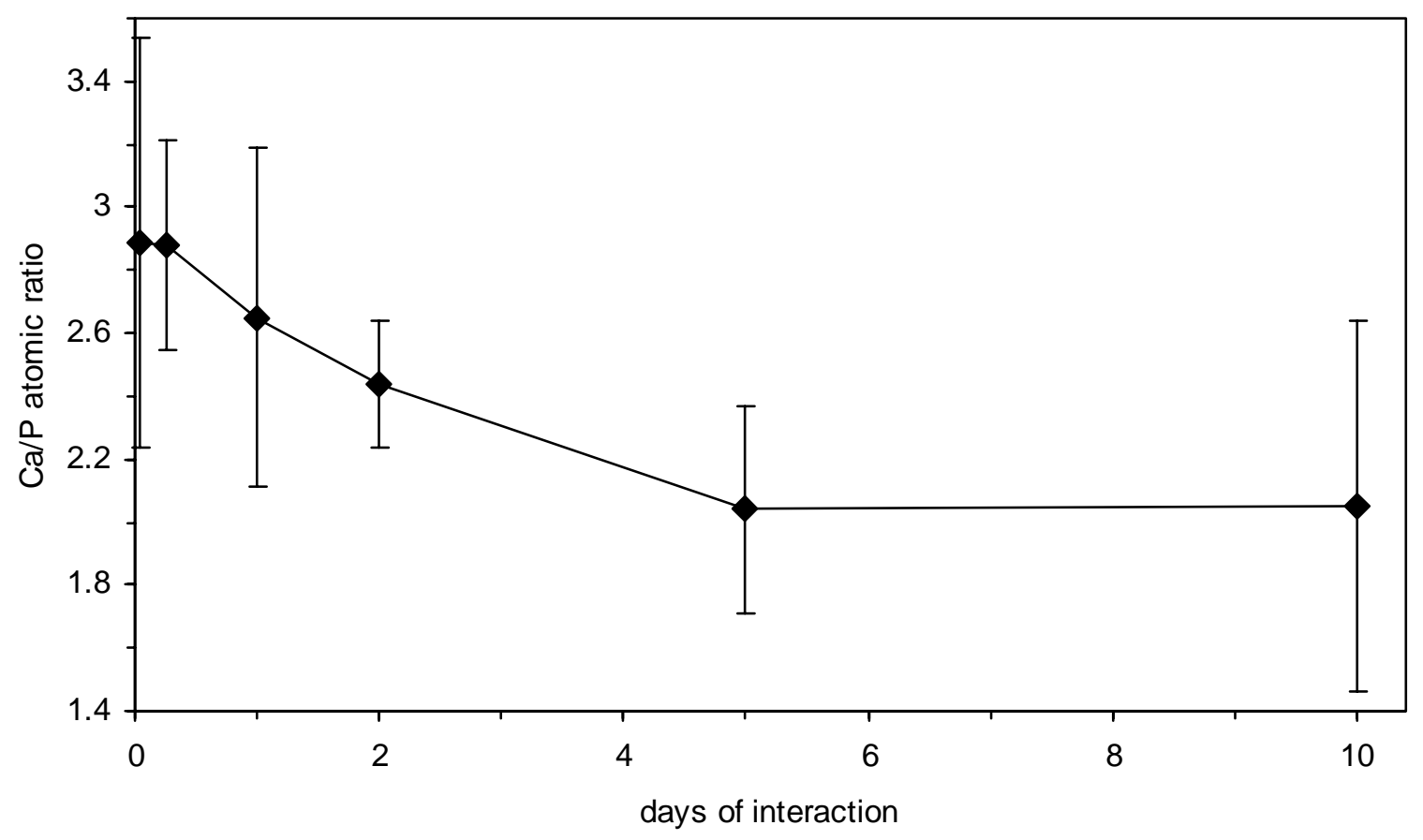

Figure 7 